ing a well-marked cracked-pot sound, undistinguishable from that of a large pulmonary cavity. Since then, I have carefully watched for the same phenomenon, and have met with it little less than a dozen times. It is most noticeable in children under or about the age of six years, although it is far from being limited to that period, for $I$ once met with it highly developed in a boy twelve years old. I have never been able to produce it unless the child's mouth has been widely opened, and have invariably noticed that where it has been most evident the percussion-sound, whilst the mouth was closed, was of a resisting, jarring, and wooden character, bearing, in fact, a strong resemblance to the wooden note already spoken of as mistakable for the cracked-pot sound. I have frequently noticed this jarring sound in the chests of children unassuciated witin the bruit, and believe it to be of very common occurrence; it is most evident whilst the mouth is kept open, and most frequently found in children with thin and flat chests. In emphysema, as well as in some cases of chronic bronchitis in young subjects, the bruit de pot fêle is occasionally met with; under the latter, I have noticed it on three or four occasions, and a striking instance of it lately occurred to me in the person of a boy, thirteen years of age, affected with emphysema and chronic cough. I have also met with it in phthisical children, where, as is often the case, patches of tubercular lung have been surrounded by healthy but probably hypertrophous tissue.

The mechanism of the bruit de pot fêle is not, perhaps, very easy of explanation. A peculiar condition of the thoracic wal is probably essential to its production, or it would be elicited in every instance of cavities of similar character known as favourable to its development, which is very far from being the case. Thinness, flatness, and flexibility of the corresponding parietes are favourable, if not necessary, to its existence. The cavity must be of some size, and must freely open into the bronchial passages. The smallest vomica in which I ever detected it, was afterwards ascertained to have been little larger than a pigeon's egr; but, as a general rule, the more extensive the cavity the more distinct the bruit. The sound seems to be produced by the sudden expulsion of the contained air, and reaches the auscultator chiefly through the patients mouth: the former being proved by the necessity (except in very rare cases, where some peculiarity in the nasal opening would appear to answer the same purpose, ) of the mouth being opened; and the latter, by the frequency with which the sound escapes detection when tho patient's face is turned away from the auscultator. The occasional occurrence of the bruit in healthy children lends additional force to such an explanation of the phenomenon. We have in children the thin thoracic wall and the free opening into the bronchial tubes. The comparative largeness of the pulmonary cells in early life, the great elasticity of the lung tissue, and the freedom of both respiratory acts, would indeed almost justify cur regarding the chest of the child as a large pulmonary cavity. Such conditions of course vary in degree in different children; but it is not surprising that, where they are most developed, wo should sometimes find the cracked-pot sound.

I have already stated that the bruit de pot fêle is not unfrequently a useful aid to diagnosis. Peing limited to the seat of its production, it will, in many instances, enable us to mark out the size and direction of the cavity. When vomice are veryolarge, and so simulating many of the physical signs of pneumo-thorax that the one condition might readily be mistaken for the other-an occurrence which has several times presented itself to me at the Consumption Hospital, - the bruit de pot felé, should it exist, will serve at once to distinguish between them. None but the inexperienced in auscultation can affirm that a pulmonary cavity is always easy to detect. It happens now and then that the sibilant or sonorous rhonchi of an accompanying bronchitis completely mask the tubercular signs. In cases also of $v$ ery chronic phthisis, especially in old persons, a cavity, although of some size, may easily escape detection, owing to the absence of secretion, combined with the old and inelastic state of the walls giving rise to but few, if any, of the usual signs of such a condition. In cases like these, -and I can call to mind three or four such, - the cracked-pot sound may come to the rescue: I remember three cases in which it was the only thing which enabled me to declare with certainty that a vomica existed; and in all of these, postmortem examinations proved the accuracy of the conclusion. It is not therefore a mere refinement, but a sign which may not only be confirmatory of others, but may sometimes be used of itself as a means of diagnosis.

The following are the conclusions at which I have arrived:-

1. The true bruit de pot fêlé is, in the adult, a certain sign of pulmonary excavation.
2. It is occasionally met with in healthy children, as well as in young subjects affected with chronic bronchitis or emphysema. It is also sometimes to be found in phthisical children during the first stage of their disease.

3 . It is easily and very frequently confounded with another percussion sound, which is indicative of very different pathological conditions.

Let me therefore plead for the old bruit de pot felle. It has often served me, and I am convinced may be useful to others. Let it not be thrown aside as a vague and unmeaning sign; rather let its difficulties, if it seem to have any, be surmounted, that it may hold the position due to it amongst the physical evidences of disease.

Clarges-street, Piccadilly, March, 1857.

\section{NOTES OF SOME CASES IN PRIVATE PRACTICE.}

BY THOMAS NEWHAM, Esq., M.R.C.S., LATR SURGEOX, ROYAL SUSSEX ARTILLXRYY.

IN presenting the notes of some few cases to the readers of The Lancet, I must claim their indulgence for the imperfect manner in which they are thrown together. I need scarcely plead, in extenuation of the faults, that the time of the medical practitioner in the country is often taken up in attending to a mass of trifling diseases, to which he is compelled to pay attention; that he has to traverse many miles of ground daily, thus. giving rise to fatigue of body, and consequently of mind; so. much so, that when the daily task is performed, he is only too. glad to obtain repose, and to take advantage of every spare moment to seek "Nature's sweet restorer, balmy sleep."

Vastly different is the case with our metropolitan brethren, and those who are engaged in practice in large towns. With both, the work is more concentrated and more easily completed, and, in addition, they can refresh their memories by attendance upon hospitals, and other public buildings, seeing every variety of case, and having the valuable co-operation of other surgeons. In the country districts, moreover, the surgeon has to battle single-handed with disease, and oftentimes with almost invincible prejudice. He requires, not only a knowledge of his profession, but that knowledge must be combined with tact and a degree of shrewdness, so as to be able not only to manage the disease, but the patient also.

In these cases, it may be said that all the methods of treatment now in vogue have not been tried. Granted; and for several reasons: sometimes from want of sanction on the part of the friends; at others, when it would have been dangerous from the impossibility of watching the cases minntely, as in those where the chest has been implicated, and which, occurring as they did in numbers at one time, rendered it difficult to watch the remedies.

Before proceeding with my cases, I shall only draw the attention of the profession to one great stumblingblock which has been always before me since I began to think of private practice: this is, the opposition to the private, and especially the country, practitioner, exercising his own free will and judgment as to treatment of cases. He is thwarted in every way, both by patients and by friends, and this will account for the apparent mal-practice I have seen when connected with hospitals. I have frequently admitted cases, and bave thought, "Well, this is curious treatment;" but now, I find that the surgeon cannot do as he pleases, and therefore arises the seeming want of skill. It is a lamentable fact that patients will loosen bandages in fractures-will not have abscesses opened, and deep-seated matter cut down on; and then, if the case does not turn out well, the unfortnnate surgeon has to bear the onus of all the patient's misdoings.

Fresh from hospital practice of every lind, I confess that this appears the worst enemy one has to contend with-this prejudice and want of confidence. Where, then, is the remedy? Is it in endeavouring as much as possible to gain the confidence of those who employ you, and gently persuading them to follow your advice? or is it in saying, that unless they do as they are told, you give up the case? Of the two, the former is the one most generally practised; and perhaps your readers will agree with me, that until some prejudices are cleared away, the public is not in a condition to bear the latter. 
Frver.

I may premise, that the cases cited have occurred in the practice of Mr. Denne; and the treatment pursued has been at all times in concert with him.

The foregoing very comprehensive title, is applied to a clisease varying in its character with topographic situation, want of good drainage and cleanliness, habits of patients, season of the year at which it breaks out, and, I believe, above all, in the constant change taking place in the system. Nothing is more patent to the common observer than the different methods in which fever has begun, ended, and been treated, within the last ten years.

Within my small experience, the attack of fever has been highly inflammatory, with cerebral complications and delirium of a fierce character, only to be net by copious bleedings and severe antiphlogistic treatment, the recovery being generally rapid and almost unaided. Now, however, the case is different. To bleed, would be to consign your patient to an untimely end.

The attack of this dire enemy is (at present) more insidious, the strongest man is prostrated, the delirium is of a muttering and atonic character, and, consequently, the whole course of treatment has undergone a change, accommodating itself to the symptoms, which apparently depend on a complete change of system from that of former years. The best proof of this latter fact is, that both methods of treatment have been successful at different times.

The district comprised in Mr. Denne's practice, is situated in a large basin, surrounded by hills of moderate altitude. The surface of this basin is flat, and scantily supplied with water The cottages of the poor (amongst whom fever is almost entirely prevalent) are badly situated, badly built, and badly drained The rooms are low, and (in the case of the bed.room) without any ventilation, except by means of the window. In many in stances, five or six persons sleep in one of these apartments; the privy is placed very near to the house, and sometimes ove an open ditch running at the back of it. Connect these fact with large families oftentimes badly fed, and I think no one will deny that if fever does not break out, and annually carry off its victims, it is only prevented doing so by an over-ruling beneficent Power. Such, however, is the case. In one or other village, typhus is always present. When the poison has exhausted itself in one locality, it springs up in another at a short distance, and, I believe, is never absent altogether.

During the last four months, it has been our lot to see a large number of cases of common continued fever, generally merging into typhus. In one large village, every cottage (with one or two exceptions) has been the scene of its ravages; and of its highly contagious character we have not entertained a doubt. Indeed, when the disease has broken out in other places, it has been traced to some labourer from the healthy village having had to work in the infected one, and to proceed home at night, thus carrying with him the seeds of poison. From the first village affected, fever was thus carried to the second, and was clearly traced to this origin.

The type of the disease was low, and the patient was attacked by what was frequently called a heavy cold,-that is, severe rigors, alternating with heat of a burning character dryness of the mucous membrane of the nose, and injection of the conjunctivæ; in some instances there was severe diarrhoea, but generally constipation; the tongue coated with a thick creamy covering, excessively tremulous, and indented at the edges; pulse rapid and very small. These symptoms, added to total prostration of strength, and utter helplessness, were observed by us for the first four days. In favourable cases, a change now took place: the skin became moister; a copions secretion took place from the nose and eyes; the tongue began to clean at the tip, and the indented edges to become less so, while the organ was protruded with more steadiness. The urine at this stage was scanty, and of a clear bright-red colour, being voided with difficilty and pain. The bowels were re lieved, the motion consisting of bile and scybalæ. In unfavourable cases, the skin continued hot and dry, with slight petechial eruption over the surface of the abdomen; the mucous membrane of the eyes and nose continued dry and injected the tongue, without cleaning, was dry and brown; the urine scanty; pulse tremulous and more rapid, 100 in a minute; the intellect clouded; and the voice whispering in character. The state of prostration was extreme. These symptoms were rendered more dangerous in many cases by laxative diarrhcea, the motions being of a horribly offensive character.

Returning to the favourable eases. A change took place on the twelfth or fourteenth day from the first attack: the skin resumed its natural functions, in excess; the whole of the tip of the tongue became clean; there was slight diarrhce, varied, by solid motions; the pulse became firmer; the urine more copious, but loaded with brick-dust-like matter, which became freely deposited; the taste, before absent, returned; the eyes were bright and clear; and at a glance, we could perceive that the patient was safe.

At this period, the unfavourable cases presented a far different aspect. There was low muttering delirium; injected conjunctivæ; a brown dry tongue, refusing to clean; pulse 120 and very tremulous; colliquative diarrhcea; urine in very small quantity and ammoniacal; loss of command over the sphincters, with a peculiar odour from the breath, reminding one of commencing putrefaction. A dry, harsh, short cough was also present, without expectoration; and pnenmonic inflammation had set in at the bases of the lungs. This state of things continuing, death closed the scene on the eighteenth to the twenty-first day from the first attack.

Treatment. - The evident disorder of the primæ viæ was met by a brisk emetic, and in cases where constipation was present by a saline purgative. In those patients where the attack commenced with diarrhcea, we found a small dose of castor oil of great service. It brought away copious motions of a solid and scybalous c'aracter, very offensive. This commencement was then followed up by a mixture composed of nitric spirit of ether, one drachrn; bicarbonate of potass, one drachm; compound infusion of gentian, three ounces; water, three ounces: one ounce to be taken every fourth hour. Our reason for combining the tonic was the low type of the disease; and we found that unless this was done, typhoid symptoms rapidly developed themselves, causing no little trouble to us, and danger to the patient. In all cases of a favourable character this course of treatment was pursued, and we did not find that the febrile symptoms were increased by the tonic.

When, however, a typhoid state ensued, with all the worst features detailed above, we were obliged to have recourse to more powerful stimulants, such as compound spirit of ammonia, with sulphuric ether, and compound infusion of gentian, together with wine and brandy ad libitum; and when colliquative diarrhoa was present, the following powder was placed on the tongue every three or four hours:-Mercury with chalk, Dover's powder, of each ten grains, eight minims; divide into six powders. This rarely failed in arresting that dangerous symptom, and at the same time soothed the system, and produced sleep, and, whenever this was produced, the patient generally rallied, and progressed favourably

The number of the cases treated amounted to about eighty, and the ages of the patients varied from one year to seventy; we did not observe that age exercised any effect upon the issue.

Three deaths occurred; in two patients from the first effects of the poison, from which no rallying took place; and in the third from pneumonia. In almost all, considerable swelling of the legs, face, and arms occurred on restoration to health, and at about six weeks from the appearance of the first symptoms. The urine at this time was clear and copious, and with no trace of albumen.

My remarks may be confined to one organ-namely, the tongue; and by this we were guided far more than by the pulse. I have said that on the first accession of the fever, this member was coated generally, not one spot being free. The first sign of amendment was in cleaning of the tip. If at this time we administered the tonic already mentioned, the coating became removed gradually from before backwards, in a semicircular line, until the patient was in a fair way of recovery. When the case assumed an unfavourable aspect, the tongue (which had previously become slightly clean) was again coated, dry, and cracked.

When the patient was old, or very young, we not unfrequently administered wine and brandy even in the first stage, and with the effect of enabling the system to meet the severe: stages of the disease. Judging from the whole number os cases, it may be laid down as a rule, that whenever the least portion of the tip of the tongue is clean you may with safety give tonics, watching them carefully, and not omitting for any slight accession of the febrile attack.

I feel quite convinced that if the system of treatment by means of febrifuges is persisted in, during attacks of fever in the present day, the patient is lost; and my recent observations on this head confirm most strongly those I made some three or four years since, and published in THE LANCET at the time; and I repeat, that, after attending to the state of the prime vix for the first two or three days, if you wish to save your patients, and combat this disease successfully, you must introduce those remedies into the system which will enable it to meet, and defeat this insidious and typhoid poison. 